Article

\title{
The Impact of Facebookers' Posts on Other Users' Attitudes According to Their Age and Gender: Evidence from Al Ain University of Science and Technology
}

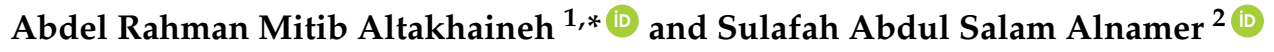 \\ 1 Department of English Language, Al Ain University of Science and Technology, Al Ain 64141, UAE \\ 2 English Department, Emirates Falcon International School, Al Ain 68338, UAE; sulafah.asa@gmail.com \\ * Correspondence: abdelrahman.takhaine@aau.ac.ae; Tel.: +971568243080
}

Received: 31 May 2018; Accepted: 1 August 2018; Published: 3 August 2018

check for updates

\begin{abstract}
This study aims at exploring the reasons that drive many Facebookers to share negative posts on Facebook, with a special focus on their gender and age. It also aims at identifying the negative attitudes and feelings that negative Facebook posts might evoke in Facebookers. Thus, a mixed-methods approach was adopted employing both a five-point agreement Likert scale questionnaire and semi-structured interviews which were conducted with 40 participants. Based on the participants' responses, the results show that many Facebookers write posts to satisfy different needs including receiving compliments and attention, sharing daily updates, showing off, and deliberately teasing others, all of which have been found to trigger feelings of jealousy, hatred, annoyance, demotivation, inferiority, and sadness. The study concludes with recommendations for further research.
\end{abstract}

Keywords: social media; Facebook; attitudes; gender; age

\section{Introduction}

Following the emergence of new technologies, the ways in which people communicate have been subject to drastic changes, especially taking into account that communication is becoming more virtual. According to Boyd and Ellison (2008), one of these new media technologies that have started to capture the attention of societies internationally is Social Media (SM). The current situation is far from being alarming since SM has given individuals the opportunity to communicate freely using language to suit their preferences (Duthler 2006). Undeniably, as noted by Sotillo (2012), one of the most commonly used means through which one could communicate and express oneself without restrictions using computer-mediated communication (CMC) is Facebook. This is due to the fact that it survives as one of the most used SM websites. Facebook has begun to be a venue for its users to share whatever is related to their personal lives; relationship status, academic achievements, work, photos, check-ins, hobbies, etc. It can be indicated that Facebook has started to serve as a preface to its users. Posts shared by Facebook users (henceforth, Facebookers) pave the way for much interaction through different Facebook tools such as 'Like', 'comment and reply', and 'share'. Unsurprisingly, the habitual use of Facebook has become integral in the lives of its users through specific routines and rituals. It has also become an indispensable tool of social capital with many people (Debatin et al. 2009). In this respect, Sotillo (2012) explained that CMC used on Facebook has been investigated from various viewpoints in numerous disciplines, including sociolinguistics, sociology, behavioural psychology, communication studies, and discourse analysis. However, examining the effect of negative Facebook posts on the feelings and attitudes of other users is an under-investigated issue. Facebookers post, interact, and 
respond to others' posts the way they do because they have different motives. As many Facebookers encourage, compliment, congratulate, or sympathise with others for whatever accomplishments, 'happy occasions', or 'sad moments' they share, undeniably, many Facebookers do not hold such positive attitudes. For a better understanding of Facebookers' negative behaviour, this study aims at investigating the main reasons that drive many Facebookers to share negative posts on Facebook. Negative posts refer to those posts that can provoke negative feelings, such as envy and hatred, in others. Specifically, it measures the extent to which gender and age can have an impact on Facebookers' negative posts, interaction on Facebook, and the negative feelings and attitudes they hold toward each other.

\section{Literature Review}

\subsection{Overview}

With the emergence of new communication technologies, several researchers, e.g., Boyd and Ellison (2008), suggested that it is crucial to examine the similarities and differences of new media communication tools in terms of features, usage, and effects. An emblematic example of a new communication technology which has become a societal staple in SM is Facebook (Boyd and Ellison 2008). Taking into consideration the millions of active users of SM websites who take part in both interpersonal interaction and self-representation, exploring SM websites such as Facebook can provide a new lens via which human interaction can be put under the microscope. In this respect, several studies have been conducted to explore this fertile area of research (Baron 2008; Caleb et al. 2009; Bazarova et al. 2012; Perez-Sabater 2012 among others). Baron (2008) has, for example, demonstrated the means by which computer-mediated technologies are affecting the ways through which individuals communicate and interact with each other. Paying special attention to SM websites, Caleb et al. (2009) investigated the ways in which individuals socially employed the status posts of SM websites such as Facebook to interact and establish their identity and their relationships with other individuals. In another recent study, Bazarova et al. (2012) explored relational concerns and self-representation via analysing different language styles on Facebook. Their study showed that the language styles used by Facebook users reveal underlying differences in the way individuals represent themselves and the way they interact with other Facebook users on the basis of the directness of their posts and comments. The results also demonstrated that words reflecting positive emotions were linked to self-reported representational concerns in status updates, whereas verbal immediacy was associated with familiarity with individuals. These studies show that, due to its common use internationally, examining Facebook posts and comments may reveal aspects related to human social behaviour that may not be detected in face-to-face interaction. Hence, this study aims to examine the reasons that drive Facebookers to share negative posts and whether their age and gender may play a role in this behaviour. The following two sections shed light on the advantages and disadvantages of using Facebook.

\subsection{Advantages of Facebook Use}

Numerous studies in the relevant body of literature have supported the fact that the advantages of using Facebook use are abundant. For example, one study showed that using Facebook is beneficial for those with low self-esteem and low-life satisfaction, as it helps them improve three dimensions of social capital: (1) 'bridging', as Facebook use can lower the barriers to communicating with or responding to others by allowing those who may shy away from initiating communication to do so through Facebook's affordances; (2) 'bonding', as Facebook may help users maintain pre-existing close relationships and keep tabs on distant acquaintances; and (3) 'maintaining social capital', as Facebook helps college students maintain relationships with high school friends, for instance, and offset the feelings of 'friendsickness' caused by loss of old friends (Ellison et al. 2007). In addition, using Facebook would help people maintain relationships as they move from one offline community to another or 
when students graduate from college. Such connections could have strong payoffs in terms of jobs, internships, and other opportunities (Ellison et al. 2007).

Moreover, intensive Facebook use was shown to be positively associated with students' social capital, that is, their life satisfaction, social trust, civic engagement, and political participation (Valenzuela et al. 2009). Specifically, through certain Facebook applications, such as 'Facebook groups', users satisfy their informational and integrative needs (Valenzuela et al. 2009). Facebook allows users to create and join groups that are based around common interests and activities (Valenzuela et al. 2009). Hence, increased participation in online and offline groups helps to build trusting relationships and, in turn, increase social capital. (Kobayashi et al. 2006).

It was also shown that the increase in status updating activity by sharing daily experiences and letting friends take part in one's life leads to more connectedness among Facebookers (Deters and Mehl 2013). Furthermore, status updates draw attention to the user and might motivate friends to initiate social interaction, which can alleviate loneliness independently of direct social feedback (i.e., responses) by friends (Deters and Mehl 2013). The content of status updates might allow a conversation to develop from a small talk to more intimate levels (e.g., 'I read you got a new job. How is that going?'), which fosters social inclusion (Aron et al. 1997; Mehl et al. 2010).

In a recent study, Facebook use was found to be positively linked to users' psychological well-being through their online social relationship satisfaction or perceived social support (Hu et al. 2017). It was also suggested that online and offline social contexts complement and reinforce each other (Hu et al. 2017). Specifically, encouraging online social relationships on Facebook can broaden Facebookers' engagement in social activities and promote self-presentation, all of which can have an impact on offline social relationships (Hu et al. 2017). Further, reinforcing offline social relationships helps people get intimacy, interpersonal trust, strong social ties, and may help Facebookers sustain more meaningful and closer social relationships online (Hu et al. 2017).

\subsection{Disadvantages of Facebook Use}

Notwithstanding the numerous advantages of using Facebook, several studies have suggested that it can be equally harmful. For instance, Facebook has the potential to provoke jealousy-related feelings and suspicion in romantic relationships (Elphinston and Noller 2011; Muise et al. 2009). Facebook intrusion, which is an excessive attachment to Facebook, interrupts people's daily tasks leading to jealousy and relationships dissatisfaction; the interpersonal nature of Facebook along with third-party threats to relationships partners encourage jealousy feelings and engagement in surveillance behaviours, which can lead to dissatisfying romantic relationships (Elphinston and Noller 2011). The fact that Facebook is a public domain enables people to access information about their partner that may be interpreted in several ways due to the misinterpretation of information out of context, which can increase people's concerns about their relationships quality (Muise et al. 2009).

Furthermore, Facebook use predicts negative shifts in cognitive and affective well-being over time; the more people used Facebook at one time, the worse they felt, and the more their life-satisfaction declined (Kross et al. 2013). This was in contrast to the 'direct' social interaction that did not predict such negative results (Kross et al. 2013). Additionally, frequent Facebook interaction has been found to be associated with greater stress directly and indirectly via a two-step pathway leading to both increased communication overload and reduced self-esteem (Chen and Lee 2013).

Facebook use has also been found to evoke feelings of envy, which is an unpleasant emotion characterized by feelings of inferiority, hostility, and resentment caused by an awareness of what others enjoy (Smith and Kim 2007). On Facebook, people share their positive experiences to develop an attractive online persona, which leads to 'envy', and that, in turn, mediates the effect of Facebook surveillance use on depression (Tandoc et al. 2015). In addition, feelings of envy can be exacerbated by passive following of others' information, which may lead to frustration, exhaustion, and decreased life satisfaction, as it triggers upward social comparison and invidious emotions (Krasnova et al. 2013). 


\subsection{The Effect of Gender and/or Age on Facebook Use}

Through reviewing the related literature, it appears that several studies have focused on the effect of gender and/or age on Facebook use (e.g., Debatin et al. 2009; Mazman and Usluel 2011; Dey et al. 2012; Mcandrew and Jeong 2012 among others). For instance, through conducting an online survey on 119 college undergraduates at a large university in the Midwestern United States followed by interviews with eight participants, Debatin et al. (2009) examined the awareness of Facebookers regarding privacy issues and the risks and benefits of using Facebook. The results showed that the respondents of the survey were predominantly females, i.e., $68 \%$ and the largest age group was between 22-24 years old. This suggests that females as well as younger participants were more interested in providing answers related to Facebook use, especially those pertaining to privacy issues and uploading personal information. Interestingly, the results revealed that even though the participants did claim to be aware of privacy issues, they did upload substantial amounts of personal information, which proposes a tendency to share personal information on Facebook regardless of privacy invasion. Despite the fact that all interviewers agreed that Facebook fuelled rumours and gossip, they kept using it since they believed that that was a mere side-effect of Facebook usage. It seems that Debatin et al. (2009) examined the extent to which Facebookers understand the issue of privacy and sharing personal information, yet they did not investigate the effect of gender and/or age on the negative posts shared on Facebook or the negative feelings such posts may provoke in others, which is the main objective of the current study.

In another study, Mcandrew and Jeong (2012) investigated how different people use Facebook through including an international sample consisting of 1026 Facebookers, 284 of whom were males and 735 were females. The participants completed an online survey related to their Facebook activities. Similarly to Debatin et al. (2009), the results revealed that the most active Facebook users were females, younger people, and other individuals who were not committed to a relationship at the time of data collection. Mcandrew and Jeong (2012) indicated that in comparison to males, younger females spent more time on Facebook, had the tendency to use profile pictures to impress people, and had more Facebook friends. In contrast, women and older participants were more interested in online family activities. Concerning relationship status, the results also demonstrated that females had more interest in knowing people's relationship status compared to males. They also kept tabs on other females' activities as opposed to males. As far as age is concerned, it was shown that older people spent less time on Facebook, were less active, and had fewer Facebook friends in comparison with younger people. It can be observed through Mcandrew and Jeong's (Mcandrew and Jeong 2012) study that age and gender can have an impact on the way individuals use Facebook on an international level. The current study, however, aims to explore the ways in which negative Facebook posts can be reflected in the attitude of Facebookers toward each other.

\section{Research Objectives}

Drawing on the previous research, it can be inferred that Facebook can be a double-edged sword for its users; as it can be advantageous, it can be equally detrimental (Hu et al. 2017). Hu et al. (2017) coined the term 'Facebook Paradox' to refer to the inconsistent and sometimes the contradictory impact of Facebook use on social relationships and psychological well-being.

The idea behind Facebook, in the first place, was to bring the world closer together, to keep up-to-date with current news, and to create a place where everyone can express what matters to them (Facebook 2017). In other words, Facebook was founded to improve people's lives socially and psychologically. Unfortunately, many Facebookers have used Facebook in a way that contradicts its original purpose. They have started to use Facebook as a malicious tool that would help them satisfy many immoral motives. Inevitably, this may evoke negative feelings in many Facebookers. It would also have a negative impact on their attitudes towards each other that may extend to face-to-face interactions offline; especially given the fact that many Facebookers know each other in person not only via Facebook. 
To the best of our knowledge, previous research on Facebook use has not addressed the effect of the gender and age of Facebookers on the type of posts they write and share on Facebook; nor has it aimed at identifying the negative feelings and attitudes such posts may provoke in others. Thus, we are left with a gap this study seeks to close to obtain a better understanding of the behaviour of Facebookers and the effect of their gender and age on the type of posts they write and share, especially in the Arab world, namely in the United Arab Emirates (UAE). Therefore, this study aims at providing potential answers to the following research questions:

(1) To what extent does the gender and age of Facebookers in Al Ain, UAE, have an impact on the type of posts they write and share on Facebook?

(2) What kind of negative attitudes and feelings that negative Facebook posts (i.e., those that provoke negative feelings such as envy) may evoke in Facebookers of different genders and ages in $\mathrm{Al}$ Ain, UAE?

The next section describes the methodology adopted in the current study.

\section{Methodology}

\subsection{Participants}

The population of the current study included the academic staff, administrative staff and students at Al Ain University of Science and Technology, Al Ain, the United Arab Emirates (UAE). However, the sample of the study included 300 participants - a mix of students, academic staff, and administrative staff, at Al Ain University of Science and Technology. They were chosen randomly through conducting stratified random sampling using lists of all staff and students at Al Ain University. Males and females are listed separately by the university, which helped in obtaining an equal division. The stratified random sampling was conducted through dividing the population into homogenous strata or groups and then selecting a random sample out of each stratum (Frankfort-Nachmias and Nachmias 2007). Our random sample was chosen based on gender, age and the duration of Facebook use. This sample was further filtered to include only those who have used Facebook for more than two years. Those who did not have enough experience with Facebook, that is, they used Facebook for less than two years, were excluded from the study after data collection in order to ensure accuracy of data. The random sample chosen in this study was taken in a number proportional to the stratum size when compared to the population (Frankfort-Nachmias and Nachmias 2007). The 240 remaining participants were divided into two groups according to their gender and age, as Table 1 below shows.

Table 1. Distribution of participants according to their gender and age.

\begin{tabular}{cc}
\hline Gender & Number of Participants (120) \\
\hline Females & 60 \\
Males & 60 \\
\hline Age & Number of Participants (120) \\
\hline Younger (17-45) & 60 \\
Older (46-60+) & 60 \\
\hline
\end{tabular}

\subsection{Data Collection}

This study adopts a mixed-methods approach, whereby researchers collect and analyse target data via employing and integrating the results arrived at from both quantitative and qualitative methods (Creswell 2008). Denscombe (2010) suggested that the purpose of adopting a mixed methods approach centres on highlighting the strength of each approach and overcoming any of their perceived weaknesses in order to offer a more comprehensive answer to the research questions. The nature of the research questions in the current study makes the use of a mixed-methods approach essential, since the 
researchers are interested in investigating the reasons that drive Facebookers to share negative posts on Facebook and whether their age and gender can have an impact on their behaviour. Thus, adopting this method may help in obtaining a good understanding of the participants' views and experiences and in providing them with the opportunity to elaborate on the answers they provided on the questionnaire. This suggests that the researcher can corroborate the results obtained via quantitative data elicitation tools through examining their answers attained via another tool, a process referred to as triangulation (Creswell 2008; Torrance 2012). In the current study, a questionnaire was used as the quantitative data elicitation tool, while a semi-structured interview was employed as the qualitative one. These two tools are discussed in the following sections.

\subsubsection{The Questionnaire}

The questionnaire of this study consisted of two sections. The first section aimed at obtaining information about the participants' gender, age, and duration of experience with Facebook. The second section aimed at collecting quantitative data. The second section consisted of 20 statements to which the participants responded using a five-point agreement Likert scale, a ubiquitous tool for the measurement of attitudes (Likert 1932) in the field of social sciences that is supported and used by multiple researchers (Ellison et al. 2007; Kalpidou et al. 2011; Altakhaineh and Zibin 2014; Altakhaineh and Rahrouh 2015; Hu et al. 2017; Altakhaineh and Rahrouh 2017). To prevent social desirability bias ${ }^{1}$ and to ensure accurate and truthful responses, the statements were tactfully worded. The tool was validated through checking the items with two professors of linguistics and any items that were deemed confusing or vague were omitted from the final version given to the participants. Additionally, the participants were not informed about the purpose of the study, they were not monitored while completing the questionnaire, and they were assured that their information would be kept confidential.

\subsubsection{The Semi-Structured Interview}

Due to the fact that this study adopts a mixed methods approach, in addition to distributing the questionnaire for quantitative data analysis, semi-structured interviews, which are the most common type of interviews used in qualitative research (Holloway and Wheeler 2010), were conducted with 40 randomly chosen participants from those who already completed the questionnaire to discuss their responses. Semi-structured interviews were shown to provide depth in the analysis of the collected data; they help the interviewer to further expand the interviewees' responses as they allow for much negotiation and discussion (Hitchcock and Hughes 1989). According to Bernard (1988), the advantage of the semi-structured interview is that the interviewer controls the process of obtaining information from the interviewee, but is free to follow new leads as they arise. Conducting the semi-structured interviews with the participants gave us a more in-depth analysis of their answers and helped us to arrive at a reasonable conclusion regarding the reasons Facebookers create and share different posts and the negative attitudes and feelings these posts evoke in them. Before conducting the interviews, written formal consents were obtained from the participants as to have their interviews tape-recorded. The participants were assured that whatever information they provided in the interviews would be kept confidential, and that the recordings of the interviews would be permanently deleted. Tape-recording the interviews helped us limit the errors that could happen by simultaneously taking notes and observing the participants (Bassey 2006). Finally, the recorded data was transcribed to qualitatively analyse the participants' responses.

1 Edwards (1957) defines social desirability bias as the tendency to report about oneself in a favourable manner. 


\subsection{Statistical Analysis}

In order to examine whether the differences between the two groups of participants, namely, males vs. females and younger vs. older Facebookers were statistically significant, a $t$-test was administered. This test is a statistical analysis tool of two populations means done via the use of statistical calculation. A $t$-test measures the $t$-statistics, degrees of freedom and the $t$-distribution in order to determine the probability of difference between the two populations. This test was used by other researchers to explore the statistically significant differences between the means of two groups (see Altakhaineh and Zibin 2014).

\section{Results and Discussion}

\subsection{Results}

For quantitative data analysis, the number of positive responses (responses that agreed with the questionnaire statements) in each of the gender and age groups was summed up. Table 2 below shows the extent to which the participants agreed with the statements.

Table 2. Percentages of the positive responses in each of the variables groups.

\begin{tabular}{|c|c|c|c|c|}
\hline \multirow{2}{*}{ The Statements } & \multicolumn{2}{|c|}{ Gender } & \multicolumn{2}{|c|}{ Age } \\
\hline & Females & Males & Younger & Older \\
\hline 1. I feel envious of the achievements my friends post on Facebook. & $57 \%$ & $32 \%$ & $55 \%$ & $38 \%$ \\
\hline $\begin{array}{l}\text { 2. Facebook users would post their marital status publicly in } \\
\text { order to receive compliments and congratulations. }\end{array}$ & $79 \%$ & $55 \%$ & $70 \%$ & $48 \%$ \\
\hline 3. Posting the graduation certificate on Facebook is pointless. & $55 \%$ & $75 \%$ & $48 \%$ & $77 \%$ \\
\hline $\begin{array}{l}\text { 4. I would share my photos on Facebook because I like receiving } \\
\text { compliments regarding the way I look or the place I am in. }\end{array}$ & $75 \%$ & $58 \%$ & $81 \%$ & $49 \%$ \\
\hline $\begin{array}{l}\text { 5. Whenever I go to a famous place, I share it on Facebook using } \\
\text { the 'Check-in' property as a matter of prestige. }\end{array}$ & $81 \%$ & $55 \%$ & $75 \%$ & $43 \%$ \\
\hline $\begin{array}{l}\text { 6. I would share the photo of my new car to tease some friends } \\
\text { whom I dislike. }\end{array}$ & $75 \%$ & $70 \%$ & $78 \%$ & $40 \%$ \\
\hline $\begin{array}{l}\text { 7. I would share my photo with my girlfriend/boyfriend to } \\
\text { tease my ex. }\end{array}$ & $88 \%$ & $68 \%$ & $81 \%$ & $23 \%$ \\
\hline $\begin{array}{l}\text { 8. I feel jealous when a friend's posts on Facebook get more 'likes' } \\
\text { than my posts. }\end{array}$ & $57 \%$ & $22 \%$ & $67 \%$ & $21 \%$ \\
\hline $\begin{array}{l}\text { 9. Some Facebook users would start to hate each other for the } \\
\text { different posts they share. }\end{array}$ & $90 \%$ & $30 \%$ & $71 \%$ & $60 \%$ \\
\hline $\begin{array}{l}\text { 10. I believe that sharing posts of achievements such as awards or } \\
\text { published works is a matter of showing off. }\end{array}$ & $57 \%$ & $88 \%$ & $75 \%$ & $52 \%$ \\
\hline 11. I hate it when people post photos of food on Facebook. & $23 \%$ & $78 \%$ & $55 \%$ & $74 \%$ \\
\hline $\begin{array}{l}\text { 12. Facebook users are savor receiving 'likes' and 'comments', so } \\
\text { they would frequently share different posts. }\end{array}$ & $95 \%$ & $35 \%$ & $91 \%$ & $32 \%$ \\
\hline $\begin{array}{l}\text { 13. Reading a political post that opposes my political view annoys } \\
\text { me and makes me hate the person who shared that post. }\end{array}$ & $63 \%$ & $35 \%$ & $78 \%$ & $57 \%$ \\
\hline $\begin{array}{l}\text { 14. I would feel envious of my friend who keeps tagging his/her } \\
\text { girlfriend/boyfriend in a comment of a romantic post. }\end{array}$ & $70 \%$ & $33 \%$ & $71 \%$ & $25 \%$ \\
\hline $\begin{array}{l}\text { 15. I would feel unmotivated when a Facebook friend constantly } \\
\text { shares their successful accomplishments on Facebook. }\end{array}$ & $68 \%$ & $21 \%$ & $69 \%$ & $49 \%$ \\
\hline $\begin{array}{l}\text { 16. I would feel sad or depressed when a friend keeps sharing sad } \\
\text { songs or poems in his/her Facebook. }\end{array}$ & $71 \%$ & $22 \%$ & $67 \%$ & $30 \%$ \\
\hline $\begin{array}{l}\text { 17. I would be angry with Facebook friends who tag each other } \\
\text { and do not tag me in their posts. }\end{array}$ & $70 \%$ & $25 \%$ & $74 \%$ & $28 \%$ \\
\hline $\begin{array}{l}\text { 18. Facebook users would feel inferior because they constantly } \\
\text { compare themselves to those who share posts showing how } \\
\text { happy they are. }\end{array}$ & $58 \%$ & $25 \%$ & $73 \%$ & $49 \%$ \\
\hline $\begin{array}{l}\text { 19. I get mad when a Facebook friend who is not of my religion } \\
\text { shares a religious post that opposes my religion. }\end{array}$ & $78 \%$ & $55 \%$ & $67 \%$ & $51 \%$ \\
\hline $\begin{array}{l}\text { 20. I hate it when a friend keeps sharing their photos, so I would } \\
\text { ignore his/her photos. }\end{array}$ & $44 \%$ & $62 \%$ & $48 \%$ & $78 \%$ \\
\hline Total mean & $68 \%$ & $47 \%$ & $70 \%$ & $46 \%$ \\
\hline
\end{tabular}


An examination of Table 2 shows that the percentage of positive responses provided by females $(68 \%)$ is higher than that of males $(47 \%)$. The same observation was noted in the responses of younger Facebookers (70\%) and older ones (46\%). This suggests that female Facebookers exhibit more negative feelings and attitudes towards Facebook posts in comparison with male Facebookers. Table 2 also demonstrates that younger Facebookers are more likely to show negative feelings and attitudes towards Facebook posts compared to their older counterparts (see Section 4.2 for more detail). In order to determine whether the differences between the responses supplied by these groups were statistically significant, two $t$-tests were calculated; one that examined the means of female and male Facebookers, and another one that examined the means of younger and older Facebookers. Table 3 presents the results of the two $t$-tests.

Table 3. The results of the $t$-test of differences between the groups in terms of gender and age.

\begin{tabular}{ccccccc}
\hline Group & Mean & Standard Deviation & $\mathbf{N}$ & DF & $\boldsymbol{t}$-Value & Sig. \\
\hline Female Facebookers & 68 & 16.82 & 20 & \multirow{2}{*}{38} & \multirow{2}{*}{3.3536} & 0.0018 \\
Male Facebookers & 47 & 21.55 & 20 & & & \\
\hline Younger Facebookers & 70 & 11.08 & 20 & \multirow{2}{*}{38} & \multirow{2}{*}{5.1251} & 0.0001 \\
Older Facebookers & 46 & 17.26 & 20 & &
\end{tabular}

A careful look at Table 3 demonstrates that the differences between the responses provided by female and male Facebookers were statistically significant $(p$ value $<0.05)$. The same observation can be noted for the second group, i.e., younger and older Facebookers.

By analysing the data collected and interviewing 40 participants to discuss their responses, reasons for sharing posts on Facebook and negative feelings evoked by Facebook posts were determined and are summarised in Table 4.

Table 4. Reasons for sharing posts and the negative feelings they evoke.

\begin{tabular}{cccc}
\hline Reasons for Sharing Posts & $\begin{array}{c}\text { Statements that } \\
\text { Indicate the Reasons }\end{array}$ & Negative Feelings & $\begin{array}{c}\text { Statements that } \\
\text { Indicate the Feelings }\end{array}$ \\
\hline $\begin{array}{c}\text { Receiving compliments, } \\
\text { likes, and comments }\end{array}$ & $2,4,12$ & Jealousy & $1,8,14,20$ \\
\hline $\begin{array}{c}\text { Sharing updates } \\
\text { about personal life }\end{array}$ & $3,5,11$ & Hate & 9,13 \\
\hline Showing off & $5,10,20$ & Annoyance & $11,13,17,19,20$ \\
\hline $\begin{array}{c}\text { Deliberately annoying } \\
\text { Facebook friends }\end{array}$ & 6,7 & Demotivation & 15 \\
\hline & & Inferiority & $1,3,18$ \\
\hline
\end{tabular}

To provide a clearer picture of the negative feelings evoked by such posts as demonstrated by gender and age groups, Figures 1 and 2 present these percentages. 


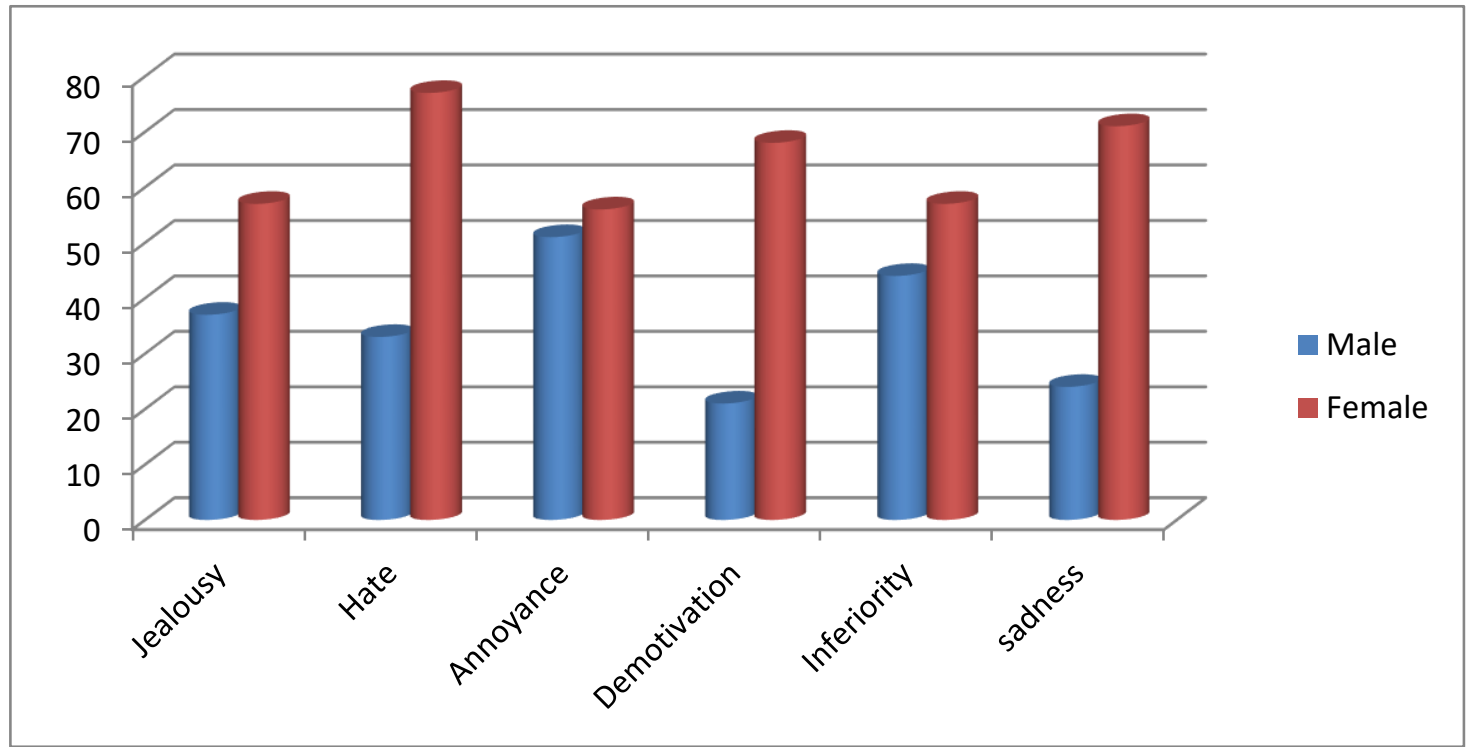

Figure 1. The negative feelings evoked by female and male Facebookers.

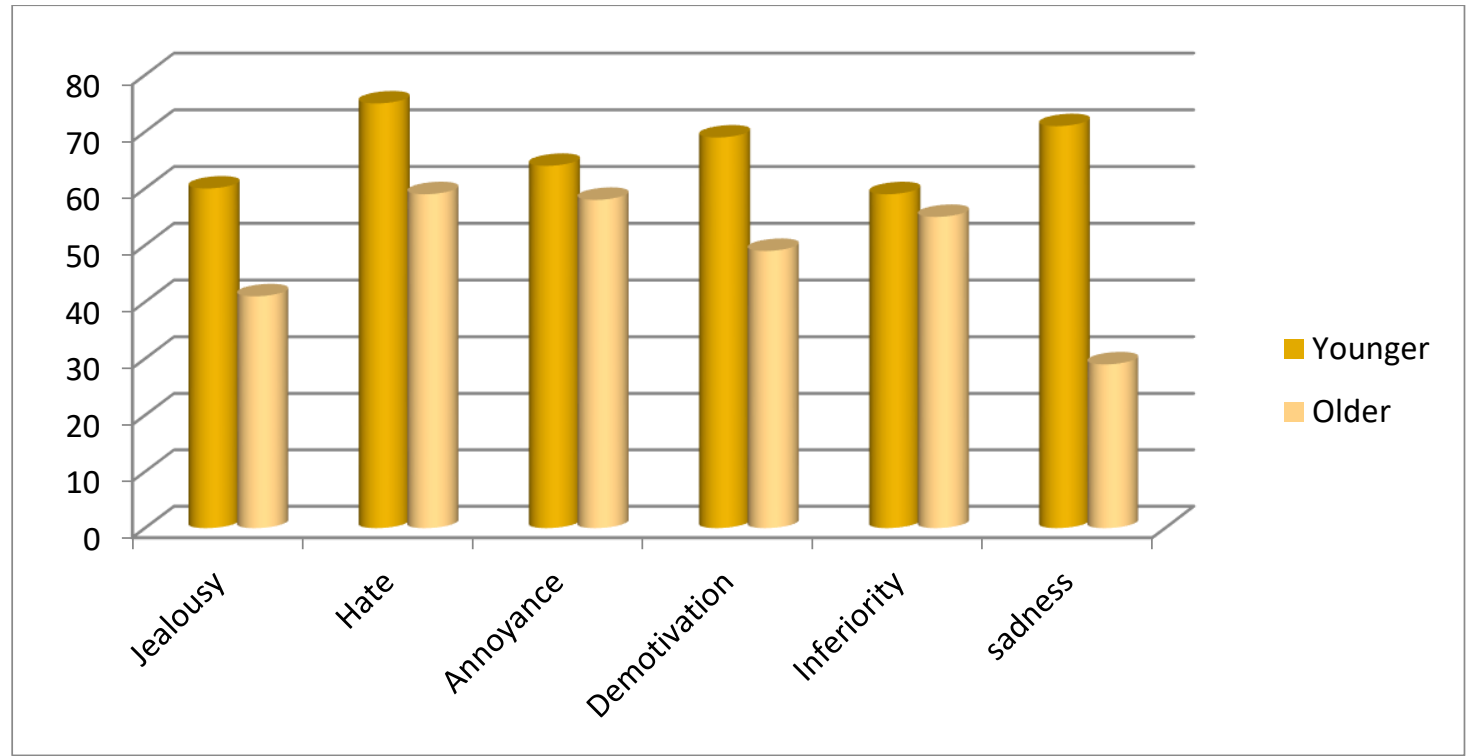

Figure 2. The negative feelings evoked by younger and older Facebookers.

Figures 1 and 2 show that sharing negative posts on Facebook is more likely to evoke negative feelings in female and younger Facebookers in comparison to male and older Facebookers. Specifically, these figures show that the percentage of negative feelings evoked by Facebook posts in female and younger Facebookers is higher compared to that of male and older Facebookers. The next sub-section further discusses the results presented in Tables 2 and 4 in order to provide potential answers to the research questions (i.e., 1 . To what extent does the gender and age of Facebookers in Al Ain, UAE have an impact on the type of posts they write and share on Facebook? 2. What kind of negative attitudes and feelings that negative Facebook posts may evoke in Facebookers of different genders and ages in Al Ain, UAE?). 


\subsection{Discussion}

To discuss the first part of the first research questions (i.e., impact of gender on the type of posts Facebookers write and share on Facebook), a careful study of the gender section of Table 4, taking into account the interviews conducted with the 40 participants, reveals many findings which are presented in the remainder of this section. First, the total mean of the females' positive responses was higher than that of the males, as shown in Table 2.

Second, as far as receiving compliments and feedback was concerned, females' positive responses outnumbered those of males; some females claimed that receiving compliments would make them feel more self-confident and more appreciated. Other female participants posited that they would feel jealous if their Facebook friends received more compliments than them.

Third, it seems like most male participants were not into sharing posts about their personal lives publically; $75 \%$ of male participants agreed that it was pointless sharing posts about the graduation certificate, the places they visit, or food they eat. During one of the semi-structured interviews, a male participant said: 'Constantly sharing posts about the incidents that happens in my life is trivial'.

Fourth, since females usually seek prestige, even online, they agreed that they would post 'check-ins', photos, and achievements on Facebook. Trudgill (1972, pp. 182-83) suggested that women tend to follow community prestige norms in contrast to the linguistic behaviour of men. Females, possibly, like attracting attention to their posts and getting likes and comments. In contrast, male participants, though not all, thought that this was a matter of showing off, and they would deliberately ignore such posts. This is similar to the results obtained by Mcandrew and Jeong (2012), who suggested that unlike males, younger females spent more time on Facebook, had the tendency to use profile pictures to impress people, and had more Facebook friends. Although some males might share different posts, photos, or 'check-ins', their intentions behind doing so, in the first place, would not be to brag about their looks, whereabouts, or achievements; they would do so just to keep a record of happy moments, as one of the male participant explained. In particular, semi-structured interviews with both male and female participants revealed that females are more likely inclined to show off on Facebook in comparison to males. These tendencies may arise from females' desire to stand out and show others how 'cool' their life is. Taking into account the arguments presented by Boyd and Ellison (2008) and Bazarova et al. (2012), such behaviour could reflect that females may care more about their self-representation and how others perceive them on SM websites, such as Facebook. Conversely, males do not seem to share the same behaviour patterns as that exhibited by females.

Fifth, both male and female participants agreed, to a great extent, that they would share photos in Facebook to deliberately annoy some Facebookers they knew in person (statements 6 and 7). Some participants claimed that this was a 'powerful way' to make some Facebook friends jealous or sad over something they desired but lacked. One male participant recalled how his friend intended to tease him by uploading photos of his newly obtained driving license and car.

Sixth, females' positive responses to statements $8,15,16,17$, and 18 greatly outnumbered those of males. As shown in Figure 1, Facebook posts are more likely to evoke negative feelings in females compared to males. Specifically, many female participants agreed that they would compare themselves to others who showed how successful and happy they were, so they would feel envious, inferior, unmotivated, and lagging behind. In this regard, Chou and Edge (2012) suggested that envy feelings can be triggered when users engage in social-comparison browsing news feed, which can cause inferiority attitudes leading to depression and poor mental health (Smith and Kim 2007). Envy, in this study, can be described as 'malicious envy' which is characterised by having no good intensions for others or by having no motivation for improving one's self (Smith and Kim 2007; Van de Ven et al. 2009). The semi-structured interviews revealed that such negative feelings evoked by Facebook posts can negatively affect social relationships between Facebookers both online and offline. One female participant mentioned that feeling resentment towards an individual as a result of a post he/she shared online can transfer to their offline relationship, causing it to be severed in some cases. However, an interesting point that was raised by a female participant pertaining to this issue during 
the semi-structured interview was that keeping pretence online and showing that she is not jealous or envious of a specific person is normal because nobody likes to look vulnerable or lose face in front of others. This type of behaviour may show that individuals care about how they appear on virtual space as much as they care about their appearance offline.

Seventh, regarding the negative feeling of 'annoyance' stated in statement 11, males thought that Facebookers ought not to post photos of food on Facebook. They claimed that doing so was immoral. Interestingly, a male reported during the semi-structured interview: 'why would I post photos of food? There is nothing to celebrate about having a sandwich for breakfast! Why don't we just sympathise with those who cannot find something to eat?' On the other hand, females liked the idea of posting photos of food along with their recipes on Facebook, as they would learn how to prepare different dishes. Some females would post photos of cooked meals just to brag about the fact that they are good cooks. With respect to statements 13 and 19, which were about political and religious posts respectively, females' positive responses were higher than those of males. Many females, though not all, would get annoyed if they encounter a political or religious post that opposed their views because they thought that whatever they believed in was right. This can be ascribed to the fact that they were brought up to these religious or political views. 'I may not show it, yet it annoys me to read posts of people who do not hold the same religious or political views as me', said a female participant during her semi-structured interview. In contrast, many males believed that Facebookers had to respect others no matter their religious or political views, and this should not interfere with people's attitudes towards each other.

Regarding the second part of the first research question (i.e., the impact of age on the type of posts Facebookers write and share on Facebook), the age section of Table 2 shows that younger participants' mean of total positive responses $(70 \%)$ was higher than that of older participants (46\%).

The positive responses of younger participants to the 20 statements outnumbered older participants' ones and even passed the average point (50\%), with the exception of their responses to statements 3,11 , and 20 . This is because older participants strongly agreed that it was pointless posting photos of 'the graduation certificate' (77\%), food (74\%), and personal photos (78\%) on Facebook. This was 'lack of maturity', as an old participant put it during the semi-structured interview. In addition, older participants, though not all, would not use Facebook to share updates and information about their personal lives. In particular, they claimed that this would put them under threats of stalkers or haters who would plot against them using their publicised personal information. This argument is similar to that of Debatin et al. (2009), who suggested that although the younger participants did claim to understand privacy issues, they did upload substantial amounts of personal information, which proposes a tendency to share personal information on Facebook regardless of privacy invasion. Further, older participants did not know how to use Facebook as younger participants did; many older participants lacked knowledge of Facebook tools such as 'check-in' or 'tag', so they would not think of Facebook as a tool to help them satisfy any malicious motives. An old participant stated during the interview: 'I use Facebook as a way to communicate with friends whom I do not see anymore'. Since older participants do not spend much time on Facebook, they would not, possibly, be as much affected with the negative Facebook posts as the younger ones. This justifies the low average of older participants' agreement with most of the statements. In contrast, many younger participants, especially young adults, who represent a core Facebook user demographic (Kross et al. 2013), would be affected by the different posts shared. This is because they agreed that they would feel jealous of achievements, photos, and relationship statuses shared by others. Furthermore, they agreed that they would feel irritated or sad when they encounter sad posts. One young participant reported: 'It really annoys me when I read someone's post about how sad and angry they feel; I would unfollow that friend!'

Generally, since younger participants spend much time on Facebook, they know how to utilise different Facebook tools of sharing photos and videos, tagging, and 'check-in' to satisfy their malicious intensions of teasing and humiliating others. 
Finally, referring back to the research questions, in sum, the results showed that the gender and age of Facebookers do have an impact on the posts they write and share on Facebook (cf. Debatin et al. 2009; Mcandrew and Jeong 2012). They also demonstrated that negative Facebook posts can evoke various negative feelings mainly in female Facebookers in comparison to male ones and in younger Facebookers compared to older ones.

\section{Conclusions}

This study has examined the effect of gender and age on the posts written and shared on Facebook and whether these posts evoke negative feelings in both groups. By adopting a mixed-methods approach, distributing questionnaires and conducting semi-structured interviews with Facebook users in Al Ain University of Science and Technology, the results showed that Facebook has been used to satisfy different needs of getting compliments and attention, sharing daily activities and updates, showing off, and irritating others, all of which have been found to evoke feelings of jealousy, hate, annoyance, demotivation, inferiority, and sadness in others. In other words, Facebook has possibly become an uncomfortable place where Facebookers hold negative attitudes toward each other. Mitigating the overall impact of negative Facebook posts is not easy, yet it is crucially suggested that Facebookers try to control their ill-intentioned acts online bearing in mind that psychological and social maladies can be as detrimental as any other physical maladies. Finally, further research studies on the extending impact of negative Facebook use on people's relationships need to be conducted. Besides, the increasing rate of suicide due to 'Facebook bullies' calls for serious investigation (see Arkell 2013).

Author Contributions: Methodology, A.R.A.; Resources, S.A.; Writing—original draft, S.A.; Writing一review \& editing, A.R.A.

Funding: This research received no external funding.

Conflicts of Interest: The authors declare no conflict of interest.

\section{References}

Altakhaineh, Abdel Rahman Mitib, and Hanan Naef Rahrouh. 2015. The use of euphemistic expressions by Arab EFL learners: Evidence from Al Ain University of Science and Technology. International Journal of English Linguistics 5: 14-21. [CrossRef]

Altakhaineh, Abdel Rahman Mitib, and Hanan Naef Rahrouh. 2017. Language Attitudes: Emirati Perspectives on the Emirati Dialect of Arabic According to Age and Gender. The Social Sciences 12: 1434-39.

Altakhaineh, Abdel Rahman Mitib, and Aseel Simak Zibin. 2014. Perception of culturally loaded words by Arab EFL learners. International Journal of Linguistics 6: 1-22. [CrossRef]

Arkell, Harriet. 2013. Coroner Warns of Dangers of Facebook after Student 19 Targeted by Young Women Bullies Online Hanged Himself. Daily Mail. November 26. Available online: http:/ / www.dailymail.co.uk/news / article-2513782/Facebook-bullies-led-suicide-student-19-hanged-himself.html (accessed on 24 July 2018).

Aron, Arthur, Edward Melinat, Elaine N. Aron, Robert Darrin Vallone, and Renee J. Bator. 1997. The experimental generation of interpersonal closeness: A procedure and some preliminary findings. Personality and Social Psychology Bulletin 23: 363-77. [CrossRef]

Baron, Naomi. 2008. Always on: Language in an Online and Mobile World. Oxford: Oxford University Press.

Bernard, H. Russell. 1988. Research Methods in Cultural Anthropology. Newbury Park: Sage.

Bassey, Eno Abasiubong. 2006. The Rise and Fall of ThisDay Newspaper: The Significance of Advertising to Its Demise. Master's dissertation, School of Journalism and Media Studies, Faculty of Humanities, University of the Witwatersrand, Johannesburg, South Africa, October 31.

Bazarova, Natalya N., Jessie G. Taft, Yoon Hyung Choi, and Dan Cosley. 2012. Managing impression and relationships on facebook: Self presentational and relational concerns revealed through the analysis of language style. Journal of Language and Social Psychology 20: 1-21. [CrossRef]

Boyd, Danah M., and Nicole B. Ellison. 2008. Social networking sites: Definition, history and scholarship. Journal of Computer-mediated Communication 13: 210-40. [CrossRef] 
Caleb, Carr, David Schrock, and Patricia Dauterman. 2009. Speech Act Analysis within Social Network Sites' Status Messages. Paper presented at 59th International Communication Association Conference, Prague, Czech Republic, May 20; p. 20.

Chen, Wenhong, and Kye-Hyoung Lee. 2013. Sharing, liking, commenting, and distressed? The pathway between Facebook interaction and psychological distress. Cyberpsychology, Behavior, and Social Networking 16: 728-34. [CrossRef] [PubMed]

Chou, Hui-Tzu Grace, and Nicholas Edge. 2012. "They are happier and having better lives than I am": The impact of using Facebook on perceptions of others' lives. Cyberpsychology, Behavior, and Social Networking 15: 117-21. [CrossRef] [PubMed]

Creswell, John W. 2008. Research Design: Qualitative, Quantitative, and Mixed Methods Approaches, 4th ed. London: Sage Publications.

Debatin, Bernhard, Jennette P. Lovejoy, Ann-Kathrin Horn, and Brittany N. Hughes. 2009. Facebook and Online Privacy: Attitudes, Behaviors, and Unintended Consequences. Journal of Computer-Mediated Communication 15: 83-108. [CrossRef]

Denscombe, Martyn. 2010. The Good Research Guide: For Small-Scale Social Research Projects, 4th ed. Maidenhead: Open University Press.

Deters, Fenne große, and Matthias R. Mehl. 2013. Does posting Facebook status updates increase or decrease loneliness? An online social networking experiment. Social Psychological and Personality Science 4: 579-86. [CrossRef] [PubMed]

Dey, Ratan, Zubin Jelveh, and Keith Ross. 2012. Facebook Users Have Become Much More Private: A Large-Scale Study. Paper presented at 2012 IEEE International Conference on Pervasive Computing and Communications Workshops, Lugano, Switzerland, March 19-23; Piscataway: IEEE, pp. 346-52.

Duthler, Kirk W. 2006. The politeness of requests made via email and voicemail: Support for the hyperpersonal model. Journal of Computer-Mediated Communication 11: 500-21. [CrossRef]

Edwards, Allen L. 1957. The Social Desirability Variable in Personality Assessment and Research. Ft Worth: Dryden Press.

Ellison, Nicole B., Charles W Steinfield, and Cliff Lampe. 2007. The benefits of Facebook "friends": Social capital and college students' use of online social network sites. Journal of Computer-Mediated Communication 12: 1143-68. [CrossRef]

Elphinston, Rachel A., and Patricia Noller. 2011. Time to face it! Facebook intrusion and the implications for romantic jealousy and relationship satisfaction. Cyberpsychology, Behavior, and Social Networking 14: 631-35. [CrossRef] [PubMed]

Facebook. 2017. Fact Sheet. Available online: http:/ / newsroom.fb.com/companyinfo/ (accessed on 26 February 2018).

Frankfort-Nachmias, Chava, and David Nachmias. 2007. Study Guide for Research Methods in the Social Sciences. London: Macmillan.

Hitchcock, Graham, and David Hughes. 1989. Research and the Teacher: A Qualitative Introduction to School-Based Research. London: Routledge.

Holloway, Immy, and Stephanie Wheeler. 2010. Qualitative Research in Nursing and Healthcare, 3rd ed.Oxford: Wiley-Blackwell.

$\mathrm{Hu}$, Xiaomeng, Andrew Kim, Nicholas Siwek, and David Wilder. 2017. The Facebook Paradox: Effects of Facebooking on Individuals' Social Relationships and Psychological Well-Being. Frontiers in Psychology 8: 87. [CrossRef] [PubMed]

Kalpidou, Maria, Dan Costin, and Jessica Morris. 2011. The relationship between Facebook and the well-being of undergraduate college students. CyberPsychology, Behavior, and Social Networking 14: 183-89. [CrossRef] [PubMed]

Kobayashi, Tetsuro, Ikeda Ken'ichi, and Kakuko Miyata. 2006. Social capital online: Collective use of the Internet and reciprocity as lubricants of democracy. Information, Community $\mathcal{E}$ Society 9: 582-611.

Krasnova, Hanna, Helena Wenninger, Thomas Widjaja, and Peter Buxmann. 2013. Envy on Facebook: A Hidden Threat to Users' Life Satisfaction? Paper presented at 11th International Conference on Wirtschaftsinformatik, Leipzig, Germany, February 27-March 1; pp. 1477-91. Available online: https://www.ara.cat/2013/01/28/ 855594433.pdf?hash=b775840d43f9f93b7a9031449f809c388f342291 (accessed on 24 July 2018).

Kross, Ethan, Philippe Verduyn, Emre Demiralp, Jiyoung Park, David Seungjae Lee, Natalie Lin, Holly Shablack, John Jonides, and Oscar Ybarra. 2013. Facebook use predicts declines in subjective well-being in young adults. PLoS ONE 8: e69841. [CrossRef] [PubMed] 
Likert, Rensis. 1932. A Technique for the Measurement of Attitudes. Archives of Psychology. New York: The Science Press. Mazman, S. Güzin, and Yasemin Koçak Usluel. 2011. Gender Differences in Using Social Networks. Turkish Online Journal of Educational Technology-TOJET 10: 133-39.

Mcandrew, Francis T., and Hye Sun Jeong. 2012. Who Does what on Facebook? Age, Sex, and Relationship Status as Predictors of Facebook Use. Computers in Human Behavior 28: 2359-65. [CrossRef]

Mehl, Matthias R., Simine Vazire, Shannon E. Holleran, and C. Shelby Clark. 2010. Eavesdropping on happiness: Well-being is related to having less small talk and more substantive conversations. Psychological Science 21: 539-41. [CrossRef] [PubMed]

Muise, Amy, Emily Christofides, and Serge Desmarais. 2009. More information than you ever wanted: Does Facebook bring out the green-eyed monster of jealousy? CyberPsychology \& Behaviour 12: 441-44.

Perez-Sabater, Carmen. 2012. The linguistics of social networking: A study of writing conventions on facebook. Linguistik Online 56: 111-30.

Smith, Richard H., and Sung Hee Kim. 2007. Comprehending envy. Psychological Bulletin 133: 46. [CrossRef] [PubMed]

Sotillo, Susana M. 2012. Illocutionary acts and functional orientation of SMS texting in SMS social networks. Aspects of Corpus Linguistics: Compilation, Annotation, Analysis 12: 1-14.

Tandoc, Edson C., Patrick Ferrucci, and Margaret Duffy. 2015. Facebook use, envy, and depression among college students: Is facebooking depressing? Computers in Human Behavior 43: 139-46. [CrossRef]

Torrance, Harry. 2012. Formative assessment at the crossroads: Conformative, deformative and transformative assessment. Oxford Review of Education 38: 323-42. [CrossRef]

Trudgill, Peter. 1972. The Social Differentiation of English in Norwich. Cambridge: Cambridge University Press.

Valenzuela, Sebastián, Namsu Park, and Kerk F. Kee. 2009. Is there social capital in a social network site?: Facebook use and college students' life satisfaction, trust, and participation. Journal of Computer-Mediated Communication 14: 875-901. [CrossRef]

Van de Ven, Niels, Marcel Zeelenberg, and Rik Pieters. 2009. Leveling up and down: The experiences of benign and malicious envy. Emotion 9: 419-29. [CrossRef] [PubMed]

(C) 2018 by the authors. Licensee MDPI, Basel, Switzerland. This article is an open access article distributed under the terms and conditions of the Creative Commons Attribution (CC BY) license (http:/ / creativecommons.org/licenses/by/4.0/). 